\title{
Effects of water load on geophysical signals due to glacial rebound and implications for mantle viscosity
}

\author{
Jun'ichi Okuno ${ }^{1}$ and Masao Nakada ${ }^{2}$ \\ ${ }^{1}$ Earthquake Research Institute, University of Tokyo, Tokyo 113-0032, Japan \\ ${ }^{2}$ Department of Earth and Planetary Sciences, Faculty of Sciences, Kyushu University, Fukuoka 812-8581, Japan
}

(Received March 9, 2001; Revised September 17, 2001; Accepted September 21, 2001)

\begin{abstract}
We investigate the effects of the ocean function on predictions of the sea-level changes and other geophysical signals due to glacial rebound. To precisely predict these signals, a realistic ocean function including the effects of the palaeotopography, the distribution of ice sheet and meltwater influx is required. The adoption of a precise ocean function is very important in simulating the observables in Hudson Bay for an earth model with a low lower mantle viscosity of $\sim 10^{21} \mathrm{~Pa}$ s. In this case, the contribution from water loads can be comparable to that from ice loads. In the Fennoscandian region, however, the predictions are less sensitive to the details of the ocean function, because the width of the Gulf of Bothnia is very small compared with that of Hudson Bay. With an assumption that the ice model is represented by ARC3+ANT4b, we have examined the viscosity structure using relative sea-levels, gravity anomaly and solid surface gravity changes in North America and northern Europe. This study suggests a lower mantle viscosity of greater than $10^{22} \mathrm{~Pa}$ s and a upper mantle viscosity of $(4 \sim 10) \times 10^{20} \mathrm{~Pa} \mathrm{~s}$.
\end{abstract}

\section{Introduction}

The rheological structure of the Earth's mantle is one of the most important factors governing mantle dynamics. To determine the rheological structure, late Pleistocene and Holocene sea-level observations in North America have extensively been examined with an assumption that they are caused by the glacial isostatic adjustment (e.g., Cathles, 1975; Wu and Peltier, 1983; Mitrovica and Peltier, 1995). These studies, in which the upper mantle viscosity was generally assumed to be $10^{21} \mathrm{~Pa}$ s obtained by Haskell (1936), have suggested the lower mantle viscosity to be about $10^{21}$ $\mathrm{Pa} \mathrm{s}$ (see a discussion of this assumption in Mitrovica, 1996). Furthermore, Peltier and Andrews (1976), Wu and Peltier (1983) and Tushingham and Peltier (1992) have argued that the sea-level predictions based on a uniform viscosity model can explain the global data base of relative sea-level changes. There are, however, a number of studies supporting a major increase in viscosity from the upper to lower mantle (e.g., Walcott, 1980; Nakada, 1983; Nakada and Lambeck, 1989; Nakada and Lambeck, 1991; Forte and Mitrovica, 1996). From independent arguments using the geoid anomalies around the subduction zone, Hager (1984) has also suggested a substantial increase in viscosity across the $670 \mathrm{~km}$ seismic discontinuity.

Sea-level variations related to the glacial rebound of Fennoscandia have been a particularly active area of study (e.g., McConnell, 1965; Cathles, 1975; Lambeck et al., 1990, 1998). Lambeck et al. (1990) have argued that the Holocene sea-level changes in northwestern Europe require

Copy right (C) The Society of Geomagnetism and Earth, Planetary and Space Sciences (SGEPSS); The Seismological Society of Japan; The Volcanological Society of Japan; The Geodetic Society of Japan; The Japanese Society for Planetary Sciences. a lithosphere of thickness between $100 \sim 150 \mathrm{~km}$, an upper mantle viscosity of about $3 \sim 5 \times 10^{20} \mathrm{~Pa}$ s and a lower manthe viscosity of about $2 \sim 7 \times 10^{21} \mathrm{~Pa} \mathrm{~s}$. Mitrovica (1996) has suggested a similar model. In contrast, Fjeldskaar and Cathles (1991) have examined shoreline tilting histories at locations near the edge of the Fennoscandian ice sheet, and have suggested an earth model which has a $50 \mathrm{~km}$ thick lithosphere, a $75 \mathrm{~km}$ thick sublithospheric low viscosity zone with viscosity of $1.3 \times 10^{19}$ and a uniform mantle viscosity of $10^{21} \mathrm{~Pa} \mathrm{~s}$. There are problems with the determination of a rheological structure of the Earth's mantle based on the sea-level variations at sites near the glaciated regions. The main one is the uncertainty with respect to the adopted ice model (Nakada and Lambeck, 1987).

More recently, radial and horizontal surface deformation rates and gravity anomaly due to the late Pleistocene glacial cycles have been also used to examine mantle viscosity and the melting histories of ice sheets (e.g., Mitrovica and Peltier, 1989; Mitrovica et al., 1994b; Kaufmann, 1997; Milne et al., 2001). James and Morgan (1990) were the first to evaluate the horizontal motions associated with the glacial isostatic adjustment using a simple disk ice load. Mitrovica et al. (1994b) predicted the present-day radial and horizontal deformation rates using the ICE-3G model (Tushingham and Peltier, 1991), and suggested that the predictions of horizontal velocity are dependent on the geometry of the late Pleistocene ice sheet and the deformation rates are very sensitive to the Earth's rheology. James and Ivins (1998) examined both the surface gravity anomaly and crustal motion caused by the past and present-day ice mass variations in Antarctica (see also Nakada et al., 2000), and concluded that viscoelastic crustal deformation rates and solid surface gravity change can be observed by modern geodetic techniques. 
The free air gravity anomaly is important for examining the lower mantle viscosity. That is, the observed negative free air gravity anomaly around the Hudson Bay has been interpreted to be the result of the incomplete postglacial rebound (Walcott, 1972). On the other hand, there are suggestions that the origin of this gravity anomaly is the result of both incomplete rebound and dynamic topography associated with convective downwelling inferred from higherthan-average mantle seismic velocities (Hager and Clayton, 1989; Forte and Mitrovica, 1996; Pari and Peltier, 1996). More recently, Simons and Hager (1997) have suggested that about half of this gravity anomaly is the result of incomplete postglacial rebound.

A realistic modelling of Earth deformation due to surface load is required in order to infer the mantle viscosity from relative sea-level changes, surface deformation rates and gravity anomaly in glaciated regions. Nakada and Lambeck (1987), for example, indicated that the Holocene sea-levels are sensitive to the Earth's response due to meltwater loading and high-degree spatial resolution of coastline geometry is required for accurate predictions at far-field sites (see also Nakada, 1986). Lambeck and Nakada (1990), Johnston (1993) and Milne and Mitrovica (1998) considered the effect of time-dependent ocean geometry on relative sea-level predictions. Mitrovica and Peltier (1991) and Johnston (1993) indicated that the effect of spatially non-uniform water load is very significant for sea-level predictions at sites near or within ice sheets. More recently, Milne (1998) and Milne et al. (1999) indicated that the change in sea-level in icecovered, subgeoidal geographic regions during periods of deglaciation are predicted incorrectly using the original sealevel equation by Farrell and Clark (1976) (see also Peltier, 1998). Milne et al. (1999) introduced a correction for the water load component of sea-level equation in ice-covered, subgeoidal geographic regions, and showed a discrepancy of 40 per cent in relative sea-level predictions around the Hudson Bay region.

This paper is an extension of Milne et al. (1999) and we use the sea-level equation formulated by Milne et al. (1999). Milne et al. (1999) examined the effect of water loads on the predictions of relative sea-levels and present-day surface deformation rates for the Laurentide region. The water loads due to glacial rebound are, however, sensitive to the size of the area covered by ice load. That is, these effects may be different for the Laurentide and Fennoscandian regions. In this study, we examine the effects of water loads on the relative sea-level changes, surface deformation rates, freeair gravity anomaly and the solid surface gravity change in Laurentide and Fennoscandian regions, and then discuss the viscosity structure inferred from these geophysical observables.

\section{Geophysical Modelling}

We describe the mathematical approach used to predict sea-level change, surface deformations and gravity anomalies on a spherically symmetric earth due to a global mass redistribution. To predict the surface deformations caused by the late Pleistocene glacial cycles, we require the Green functions for sea-level change, radial and horizontal displacements, and gravity anomaly due to an impulsive sur- face load. These Green functions consist of combined or scaled Love numbers (e.g., Farrell and Clark, 1976; Mitrovica and Peltier, 1989; Mitrovica et al., 1994a). Peltier (1974) has formulated the Love numbers of a Maxwell viscoelastic earth by applying the correspondence principle to the elastic equations formulated by Farrell (1972).

The Green functions for the sea-level change, radial and horizontal displacements, the free air gravity anomaly and the solid surface gravity anomaly are given by (e.g., Farrell and Clark, 1976; Mitrovica and Peltier, 1989; Mitrovica et al., 1994a)

$$
\begin{gathered}
G_{\mathrm{sl}}(\gamma, t)=\frac{a g}{M_{e}} \sum_{n=0}^{\infty}\left[\delta(t)+k_{n}(t)-h_{n}(t)\right] P_{n}(\cos \gamma) \\
G_{u}(\gamma, t)=\frac{a}{M_{e}} \sum_{n=0}^{\infty} h_{n}(t) P_{n}(\cos \gamma) \\
\vec{G}_{v}(\gamma, t)=\frac{a}{M_{e}} \sum_{n=0}^{\infty} l_{n}(t) \frac{\partial}{\partial \gamma} P_{n}(\cos \gamma) \vec{\gamma} \\
G_{\mathrm{FA}}(\gamma, t)=\frac{g}{M_{e}} \sum_{n=0}^{\infty}\left[(n+2) \delta(t)-(n-1) k_{n}(t)\right] \\
G_{\mathrm{SG}}(\gamma, t)=\frac{g}{M_{e}} \sum_{n=0}^{\infty}\left[n \delta(t)+2 h_{n}(t)-(n+1) k_{n}(t)\right] \\
\cdot P_{n}(\cos \gamma)
\end{gathered}
$$

where $a$ is the Earth's radius, $M_{e}$ is the Earth's mass, $g$ is the gravitational acceleration at the Earth's surface, $\delta$ is the delta function, $P_{n}$ denotes the Legendre polynomial of degree $n$ and $\gamma$ is the angle between an observation point $(\theta, \phi)$ and an impulsive load point $\left(\theta^{\prime}, \phi^{\prime}\right)$ with $\theta$ and $\phi$ the colatitude and east longitude, respectively. $\vec{\gamma}$ is a horizontal unit vector in the direction of the great circle extending from the load point to the observation point. The functions $h_{n}(t), l_{n}(t)$ and $k_{n}(t)$ are dimensionless Love numbers of the radial and horizontal displacements and the potential perturbation due to the point load, respectively (e.g., Peltier, 1974).

We define an arbitrary surface load $L(\theta, \phi, t)$ by

$$
L(\theta, \phi, t)=\rho_{i} I(\theta, \phi, t)+\rho_{w} W(\theta, \phi, t)
$$

where $\rho_{i}$ and $\rho_{w}$ are the densities of ice and water, $I$ is the ice height, and $W$ is the ocean depth.

The response of a spherically symmetric, self-gravitating, viscoelastic earth to arbitrary surface load, $L$, can be calculated by convolving the load, in space and time dimensions, with appropriate Green function. Based on (1)-(5) we can calculate the response, $R$ and $\vec{R}$, due to surface loading, which are given by

$$
\begin{array}{r}
R_{[\mathrm{sl}, u, \mathrm{FA}, \mathrm{SG}]}(\theta, \phi, t)=\int_{-\infty}^{t} \int_{0}^{2 \pi} \int_{0}^{\pi} a^{2} L\left(\theta^{\prime}, \phi^{\prime}, t^{\prime}\right) \\
\cdot G_{[\mathrm{sl}, u, \mathrm{FA}, \mathrm{SG}]}\left(\gamma, t-t^{\prime}\right) d \phi^{\prime} \\
\cdot \sin \theta^{\prime} d \theta^{\prime} d t^{\prime} \\
\vec{R}_{v}(\theta, \phi, t)=\int_{-\infty}^{t} \int_{0}^{2 \pi} \int_{0}^{\pi} a^{2} L\left(\theta^{\prime}, \phi^{\prime}, t^{\prime}\right) \\
\cdot \vec{G}_{v}\left(\gamma, t-t^{\prime}\right) d \phi^{\prime} \sin \theta^{\prime} d \theta^{\prime} d t^{\prime}
\end{array}
$$



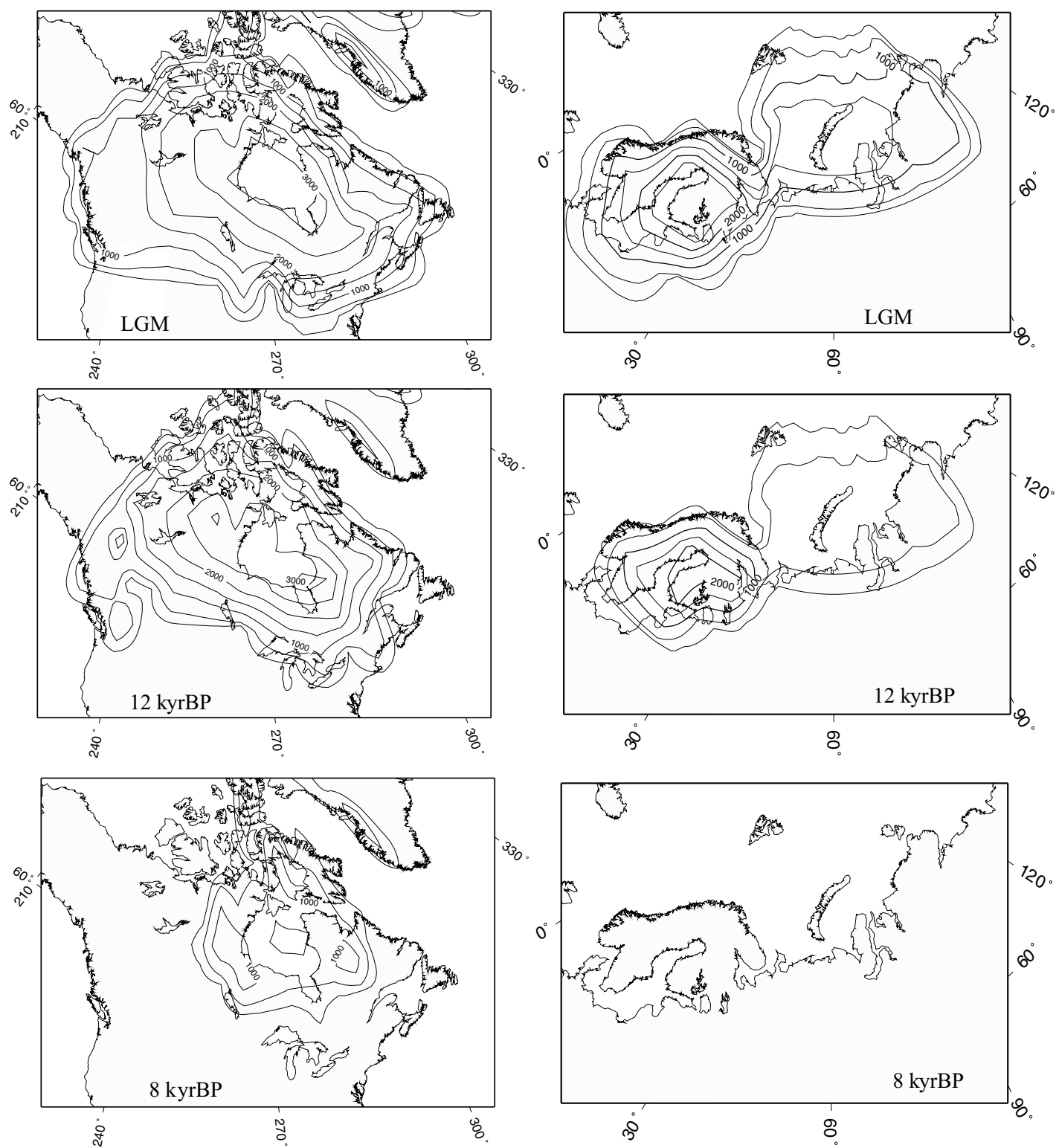

Fig. 1. Ice distribution maps of ice model ARC3. Contour interval is $500 \mathrm{~m}$.

In the calculations of the responses, $R$ and $\vec{R}$, we need surface Love numbers for a given earth model, ice model $I$ and time-dependent water load $W$. For adopted earth and ice models, the time-dependent water load associated with the isostatic adjustment process is evaluated by first solving Eq. (7). Then we solve sea-level equation (Farrell and Clark, 1976) defined by

$$
W(\theta, \phi, t)=O(\theta, \phi, t)\left[\frac{R_{\mathrm{sl}}(\theta, \phi, t)}{g}+c(t)\right]
$$

where $O$ is the time-dependent ocean function, equaling 1 over the oceans and zero over the lands (e.g., Munk and MacDonald, 1960). The second term of Eq. (9) is required for conservation of mass, and is given by

$$
c(t)=-\frac{M_{i}(t)}{\rho_{w} A_{0}}-\left\langle\frac{R_{\mathrm{sl}}(\theta, \phi, t)}{g}\right\rangle_{O}
$$

where $M_{i}$ is the change in the total mass of the ice at time $t$, positive for accretion and negative for melting (Nakada and
Lambeck, 1987), $A_{0}$ is area of ocean and \langle\rangle$_{O}$ denotes the mean volume of variable inside the brackets over the oceans.

To solve Eq. (9) numerically, several approaches have been introduced (e.g., Wu and Peltier, 1983; Nakada and Lambeck, 1987; Mitrovica and Peltier, 1991; Johnston, 1993). We adopt the pseudospectral approach formulated by Mitrovica and Peltier (1991).

\section{Theoretical Characteristics of the Sea-Level Prediction and Other Geophysical Signals}

In the calculations of sea-level variations and other geophysical signals, we use an Earth model characterized by an elastic structure given by seismically determined Preliminary Reference Earth Model (PREM) (Dziewonski and Anderson, 1981). We also adopt two viscosity structure models denoted by A and B in this section. Model A is a uniform viscosity model with viscosity of $10^{21} \mathrm{~Pa} \mathrm{~s}$ for the entire mantle. In model $\mathrm{B}$, the upper mantle viscosity 


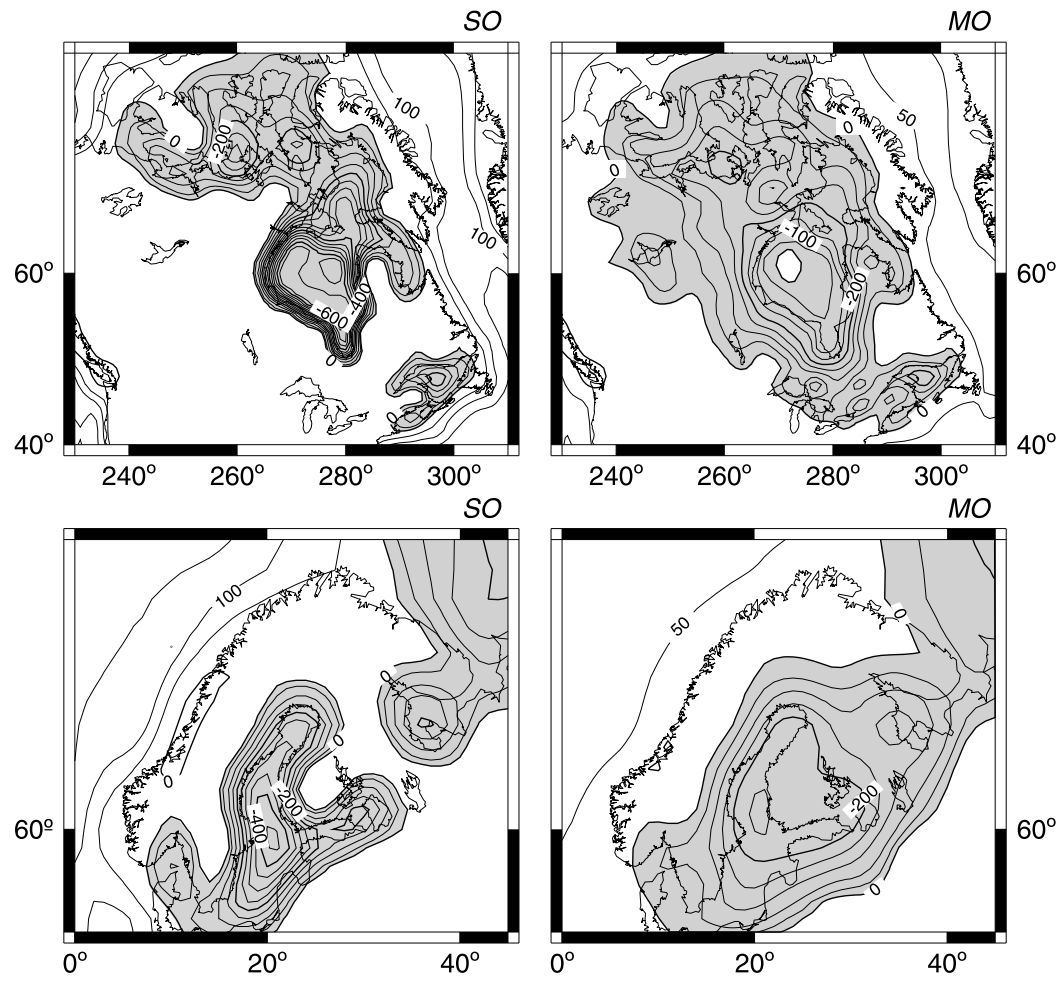

Fig. 2. Spatial variations of water load during the past $18 \mathrm{kyr}$ for the Laurentide and Fennoscandian regions. Contour unit is m. The positive value indicates the loading and the negative value indicates the unloading (shaded region).

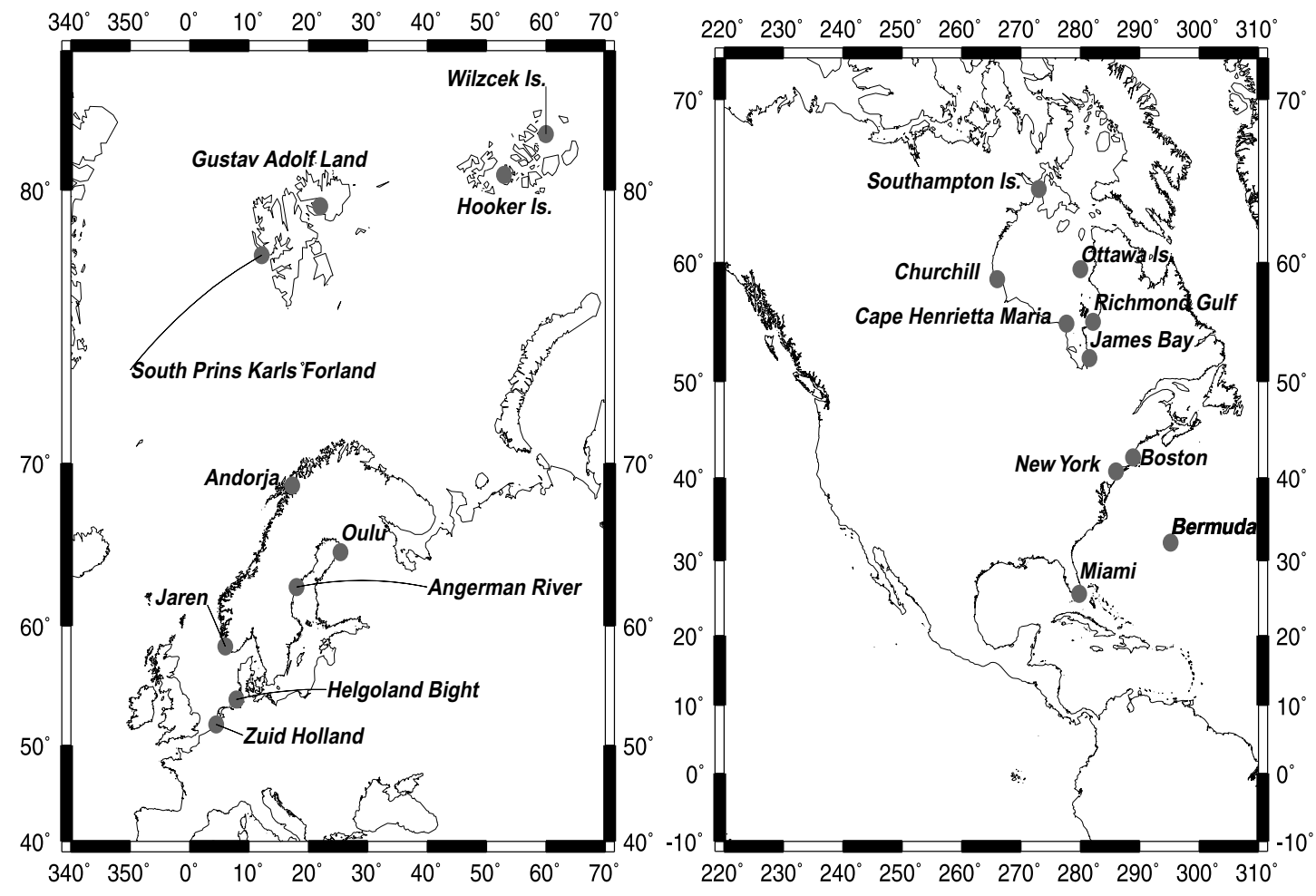

Fig. 3. Location maps for relative sea-level observations and predictions. 

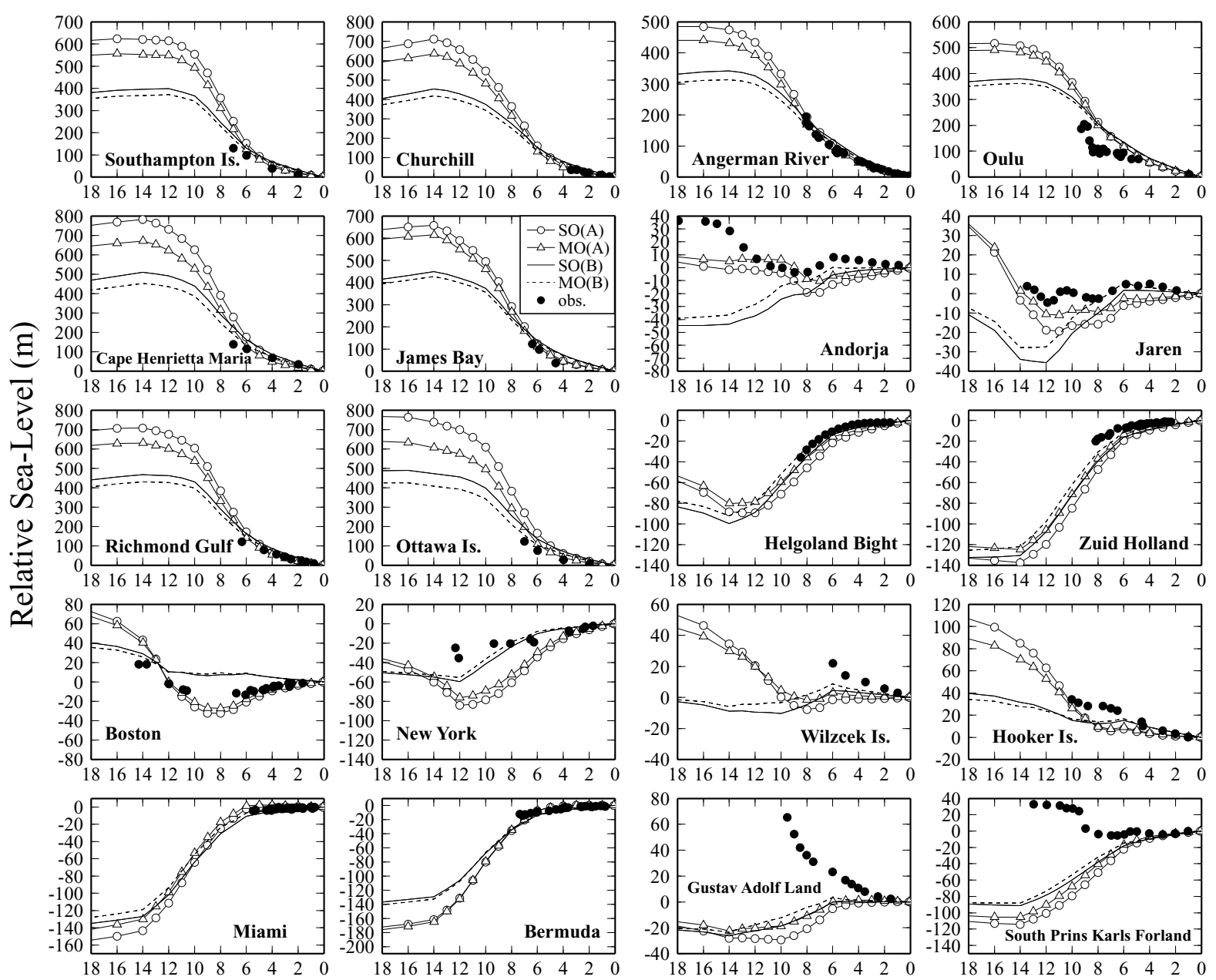

Time (kyrBP)

Fig. 4. Relative sea-level curves for the Laurentide and Fennoscandian regions. Predictions are based on two earth models, i.e., model A with a uniform viscosity of $10^{21} \mathrm{~Pa}$ s for the entire mantle, and model B with the upper and lower mantle viscosities of $10^{21} \mathrm{~Pa} \mathrm{~s}$ and $10^{22} \mathrm{~Pa}$ s, respectively. The thickness of elastic lithosphere is $100 \mathrm{~km}$ for both models. In these calculations, we use two ocean function models, SO and MO. Model SO is based on the present topography and model MO is constructed by considering the palaeotopography, ice sheet distribution and water influx (Milne et al., 1999).
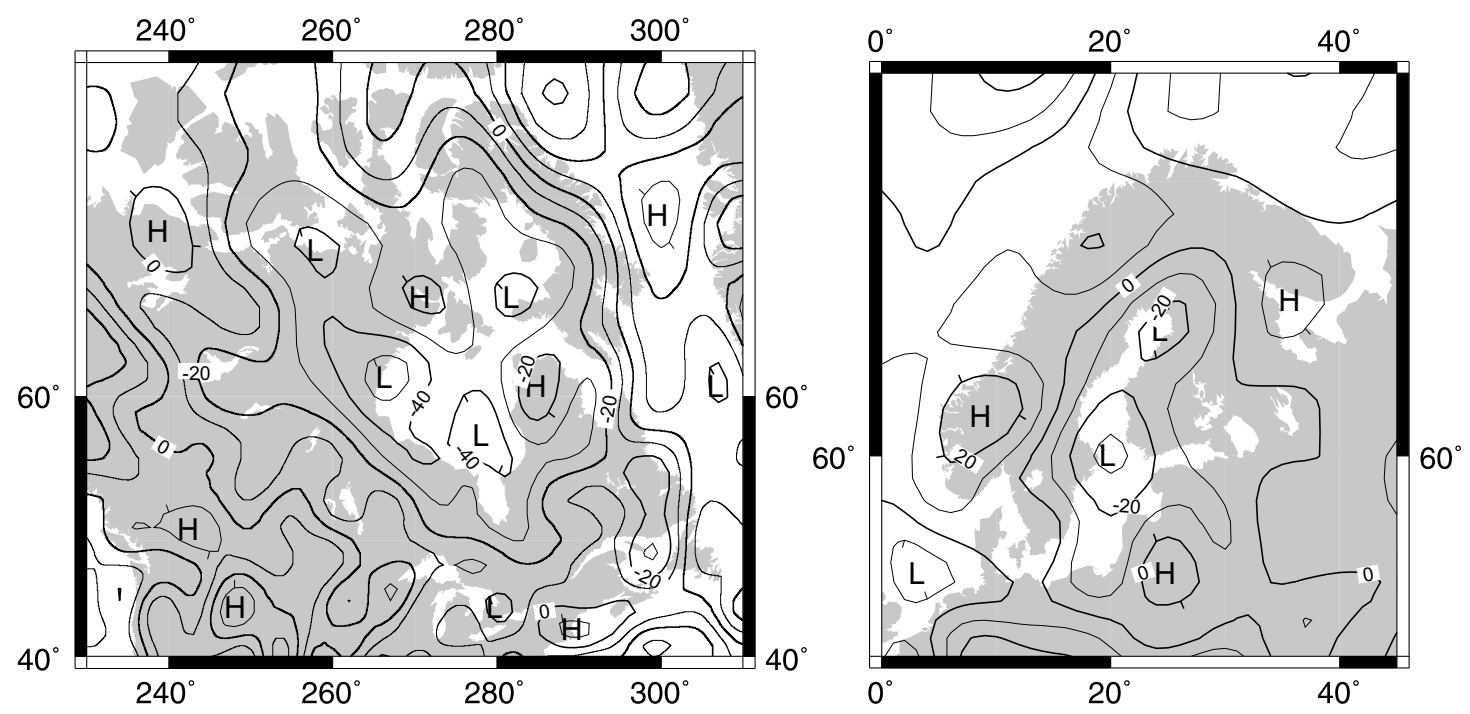

Fig. 5. Observed free air gravity field from spherical harmonic model EGM96 obtained by Lemoine et al. (1998). 
is $10^{21} \mathrm{~Pa} \mathrm{~s}$ and the lower mantle viscosity is $10^{22} \mathrm{~Pa} \mathrm{~s}$. The thickness of elastic lithosphere is $100 \mathrm{~km}$ for both models. The ice models adopted here are ARC3 (Nakada and Lambeck, 1988a) for the Arctic model and ANT4b (Nakada and Lambeck, 1988a) for the Antarctic model with a mid- to late-Holocene melting. ARC3 consists of the ICE1 model (Peltier and Andrews, 1976) for North America, Greenland and Fennoscandia with additional Barents and Kara Sea ice sheets. The ANT4b ice model was originally generated from the maximum reconstruction in Antarctica by Denton and Hughes (1981). A minor Holocene melting of equivalent sea-level of 2-3 m for ANT4b is supported by sealevel observations in the far-field (Nakada and Lambeck, 1988a; Okuno and Nakada, 1998) and those from British Isles (Lambeck et al., 1996). Equivalent sea-level (ESL) is defined as (meltwater volume)/(area of ocean surface). Figure 1 shows the spatial variations of the Laurentide,
Fennoscandian and Barents-Kara Sea ice sheets of model ARC3.

To obtain the accurate sea-level predictions, it is important to precisely evaluate the spatially non-uniform water load (Mitrovica and Peltier, 1991; Johnston, 1993). In this study, we use an iterative pseudospectral method formulated by Mitrovica and Peltier (1991). The water load term for the first iteration is calculated on an assumption that the meltwater load is equal to a spatially uniform "eustatic" sealevel. The water load for a second iteration is the spatially non-uniform sea-level change calculated by first iteration. Our calculation converged sufficiently by the second iteration and further iteration is not required.

We examine the effect of varying the treatment of the ocean function on predictions of sea-level and other geophysical signals. The modelling of the ocean function is very important in calculating the sea-level changes for
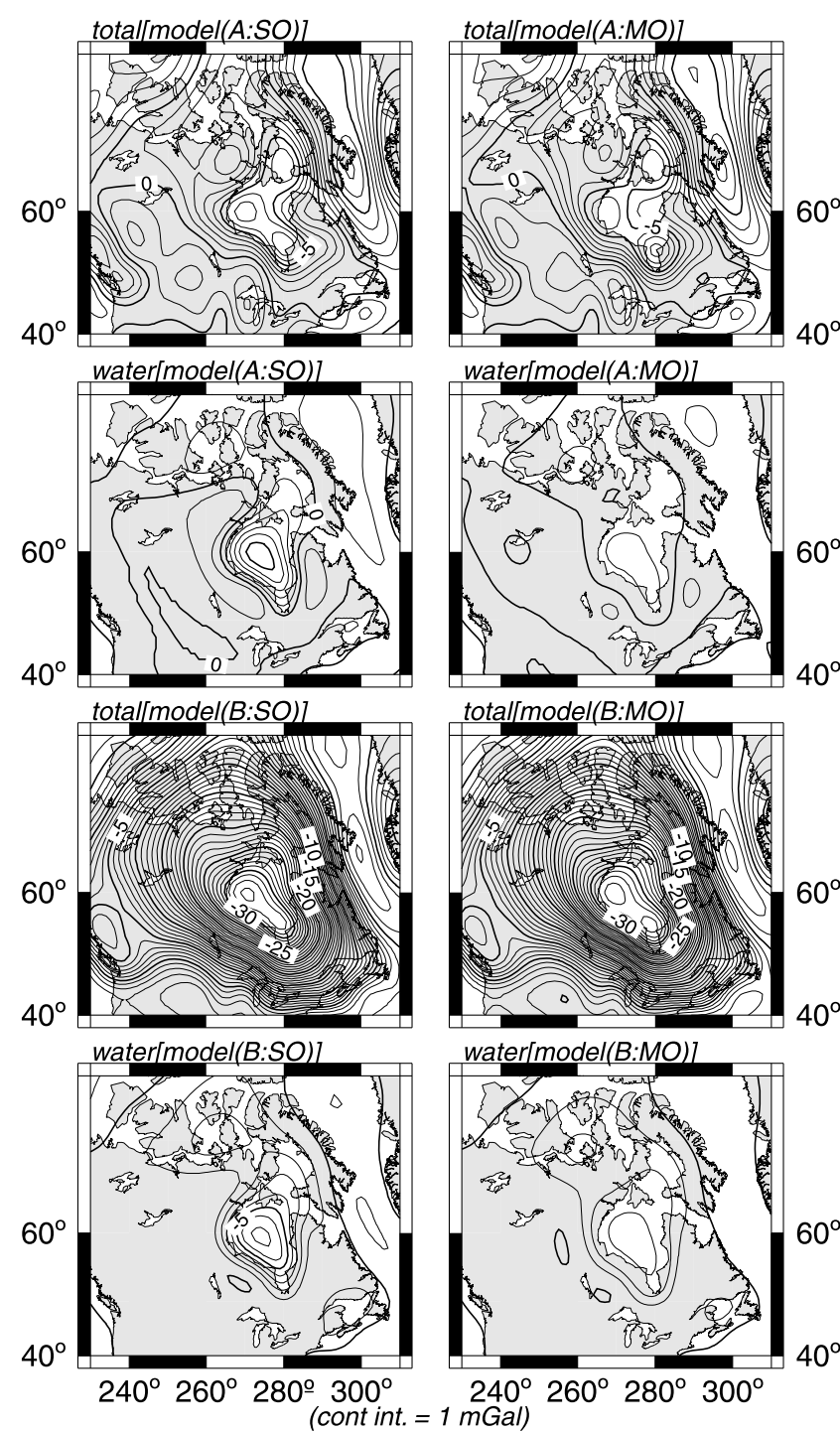

Fig. 6. Predictions of present-day free air gravity anomaly and its component by water loads in the Laurentide region. The ice model is $\mathrm{ARC} 3+\mathrm{ANT} 4 \mathrm{~b}$ and viscosity models are A and B. Contour interval is $1 \mathrm{mGal}$. For the model $\mathrm{SO}$, water load component is significant for model A. In contrast, water load component is insignificant for model MO
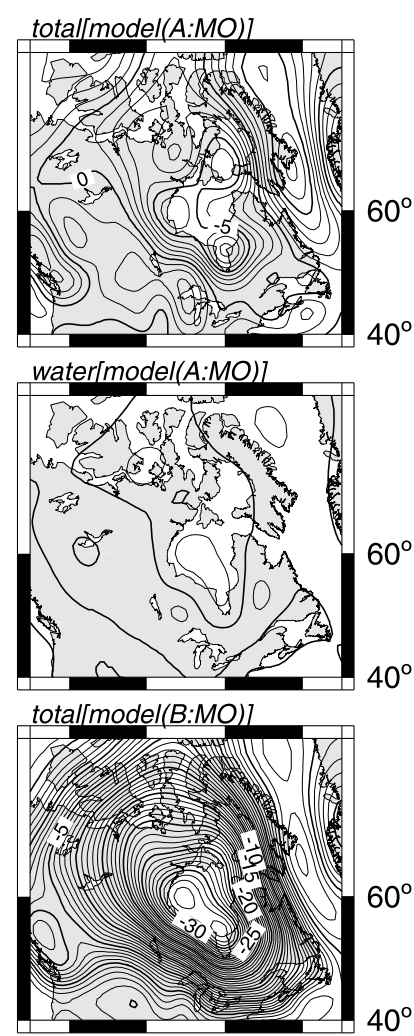

$60^{\circ}$
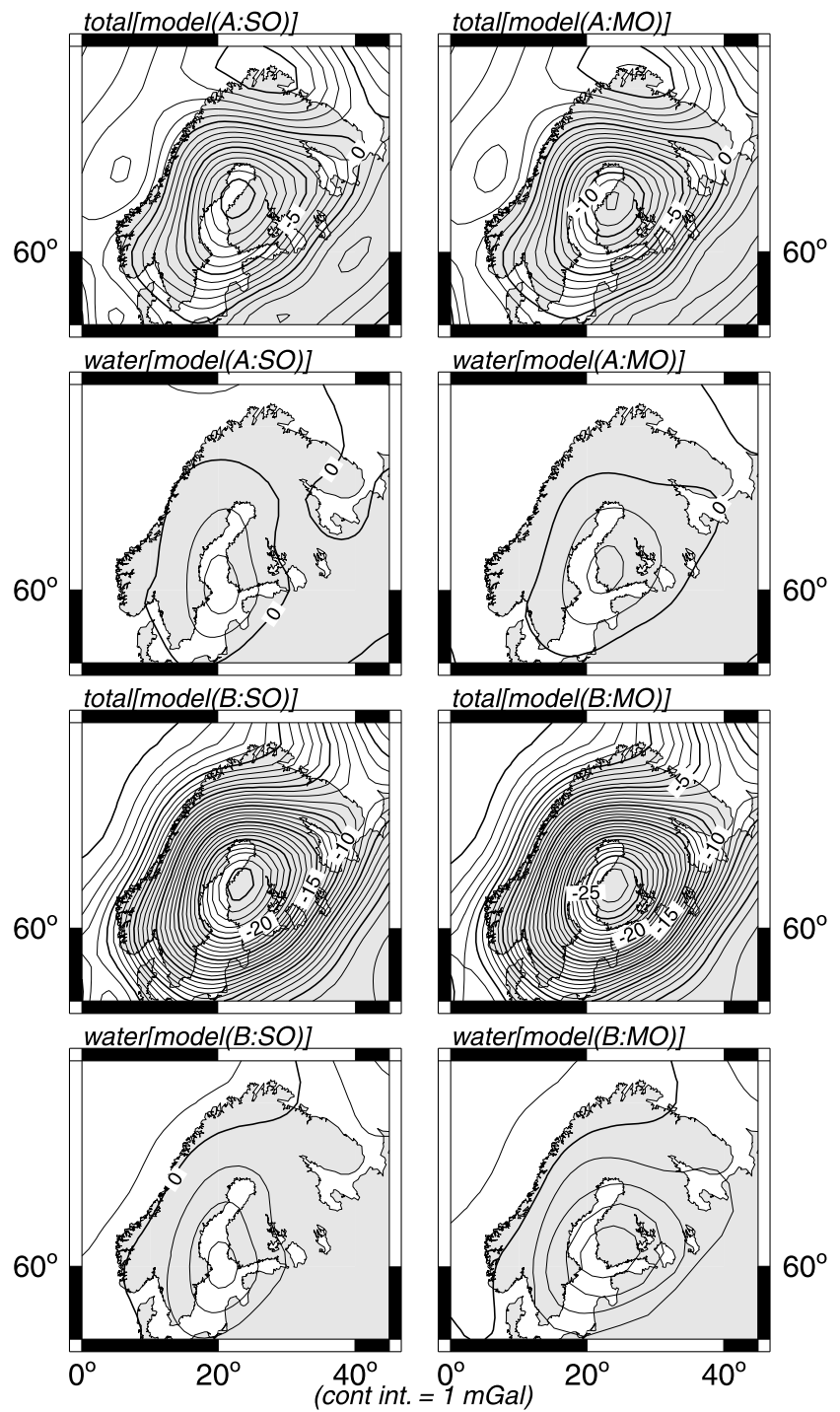

Fig. 7. Predictions of present-day free air gravity anomaly and its component by water loads in the Fennoscandian region. The ice model is $\mathrm{ARC} 3+\mathrm{ANT} 4 \mathrm{~b}$ and viscosity models are A and $\mathrm{B}$. Contour interval is $1 \mathrm{mGal}$. The difference between the water load components for models SO and MO is very small, and predictions of free-air gravity anomaly are less sensitive to the adoption of the ocean function. 
glacial regions characterized by both large crustal uplift due to glacial rebound and great ice sheets covering these regions (e.g., Milne et al., 1999). In this calculation, we employ two types ocean functions. One is a time-dependent ocean function based on the present topography, and referred to as model SO. The other is the ocean function formulated by Milne et al. (1999), and referred to as model MO. Milne et al. (1999) used an ocean function based on palaeotopography including the height of ice sheet, in which they considered the water loads due to influx of meltwater to subgeoidal solid surface regions once covered with the marine-based late Pleistocene ice sheets.

We first examine the spatial distribution of the water load during the past $18 \mathrm{kyr}$. Figure 2 depicts these values in North America and northern Europe calculated for earth model A. In this figure, negative value indicates the unloading caused by crustal uplift and positive value indicates loading. These results imply that the water loads for model SO concentrate on the regions of Hudson Bay, Gulf of Bothnia and Barents Sea. On the other hand, the magnitude of water load

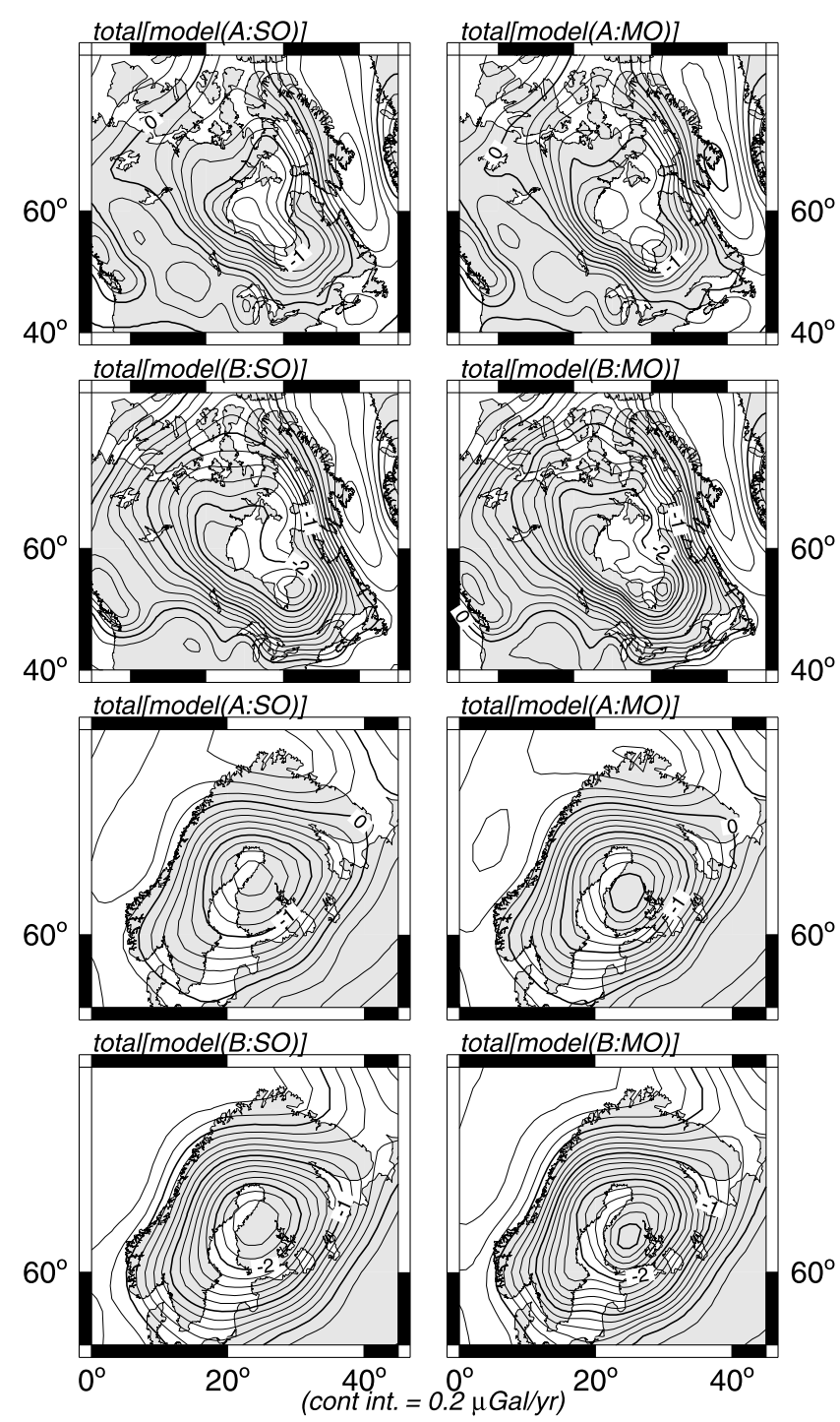

Fig. 8. Predictions of solid surface gravity changes for earth models A and B. Ice model is ARC3+ANT4b. Contour interval is $0.2 \mu \mathrm{Gal} / \mathrm{yr}$. for model MO is generally smaller than that for model SO, and water loads for model MO distribute over the wide area relative to that for model SO. Thus, there is a significant spatial difference of water loads between these two type ocean functions. Hudson Bay and Gulf of Bothnia are located on the central part of the Laurentide and Fennoscandian ice sheets, respectively, and significant water loads are predicted in those regions for model SO. This implies that predictions with an ocean function of MO model correspond to those with a thin ice load model for model SO (see Fig. 4). ARC3 model has a maximum melted ice thickness of about $3500 \mathrm{~m}$ in the central part of the Laurentide ice sheet. The thickness of ICE-3G model (Tushingham and Peltier, 1991) is about $3000 \mathrm{~m}$. The difference of the melted ice thickness between these ice models is similar to the difference of the thickness of the water load between these ocean function models, indicating that a realistic modelling for water load is very important to construct the ice model (see also Milne et al., 1999).
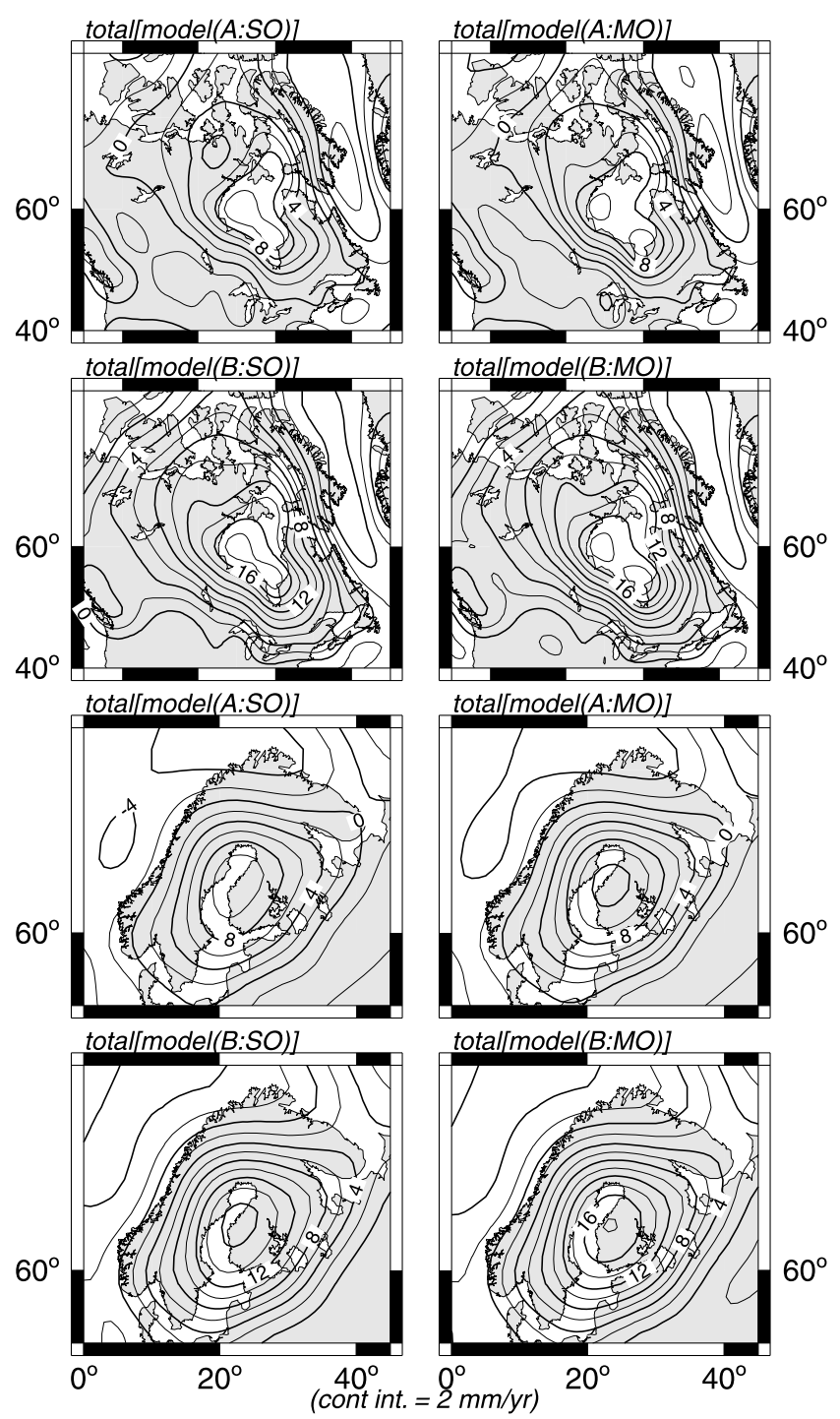

Fig. 9. Predictions of the change in vertical crustal motions for earth models $\mathrm{A}$ and $\mathrm{B}$. Ice model is $\mathrm{ARC} 3+\mathrm{ANT} 4 \mathrm{~b}$. Contour interval is $2 \mathrm{~mm} / \mathrm{yr}$. 
We calculate the relative sea-level changes at sites shown in Fig. 3, in which observations for these sites have been compiled by Walcott (1972), Tushingham and Peltier (1991) and Lambeck et al. (1998). Figure 4 depicts the relative sea-level curves in glaciated and intermediate fields for the Laurentide and Fennoscandian ice sheets. Predictions during the postglacial phase are less sensitive to the adopted ocean function. In the central part of Laurentide ice sheet, however, a significant difference can be seen for the late glacial sea-level predictions with a uniform viscosity model A. Thus, sea-level predictions for model MO are lower than those for model SO, because the magnitude of the water load for MO is significantly smaller than that for model SO (see Fig. 2 in this study and figure 7 in Milne et al., 1999). In the Fennoscandian region, sea-level predictions are not so sensitive to the adopted ocean function. These results may be attributed to the difference of the width of two gulfs. In viscosity model with a higher lower mantle viscosity (model B), the difference between the predictions of these two ocean function models is smaller than that for model A.

Figure 5 shows the observed free air gravity anomaly inferred from recent satellite model (EGM96) (Lemoine et al., 1998). The peak negative anomalies are observed at Hudson Bay and Gulf of Bothnia regions, and those are about -50 $\mathrm{mGal}$ in Hudson Bay and about -30 to $-20 \mathrm{mGal}$ in Gulf of Bothnia. Figures 6 and 7 illustrate the predicted presentday free air gravity anomalies and the component by water loads. For the model MO, the gravity anomaly due to water loading is more than $-5 \mathrm{mGal}$ in Hudson Bay and Gulf of Bothnia for the viscosity models $\mathrm{A}$ and $\mathrm{B}$, and spatial variations of the total free air gravity anomaly are dominantly attributed to the ice load component. In model SO, however, the magnitude of the water load is significant for the Hudson Bay region, and its contribution to the total gravity anomaly is important, particularly, for the model A with a uniform viscosity. Free-air gravity anomalies due to the water load for the model SO are relatively insensitive to the viscosity of the lower mantle, and those values are $-(5$ to 7$) \mathrm{mGal}$ in Hudson Bay and -(1 to 2) mGal in Gulf of Bothnia. This is because the gravity anomaly due to the water load depends on the relaxation time for a typical wavelength of the scale of Hudson Bay and Gulf of Bothnia, and those are mainly sensitive to the upper mantle viscosity. On the other hand, the free-air gravity anomalies due to the ice loads are very sensitive to the lower mantle viscosity and increase as the lower mantle viscosity increases. The contribution due to the ice load for model B is, therefore, significantly larger than that for water loads, and the total free-air gravity anomaly is relatively insensitive to the ocean function. In the Fennoscandian region the difference between the water loads for these ocean functions is relatively small, and the free-air gravity anomalies are insensitive to the adopted ocean function.

The predicted rates of solid surface gravity change ( $\mu \mathrm{Gal} / \mathrm{yr}$ ) are shown in Fig. 8. In the Fennoscandian region, the minimum values for model $\mathrm{MO}$ are slightly smaller than those for model SO regardless of the viscosity models. In the Hudson Bay region, predictions for a uniform viscosity model $\mathrm{A}$ are somewhat sensitive to the ocean function. The peak anomalies exist nearer the center of Hudson Bay for model SO. In contrast, peak anomalies for model MO are located in James Bay, coinciding with the area in which the ice thickness during the stage from the LGM to $12 \mathrm{kyrBP}$ exceeds $3000 \mathrm{~m}$. Thus, the spatial pattern is determined by total surface loads including ice and water loads. Results for model B are insensitive to the ocean function, because the solid surface gravity change is mainly determined by ice loads as inferred from the predictions of the free-air gravity anomaly. The rates of solid surface gravity due to glacial rebound are mainly controlled by the free-air gravity component associated with the vertical movement (Fig. 9), indicating a good correlation between these predictions (Mitrovica et al., 1994b; James and Ivins, 1998).

The horizontal motions shown in Fig. 10 are less sensitive to water loading for both Laurentide and Fennoscandian regions. The predicted horizontal motion is sensitive to the lower mantle viscosity (Mitrovica et al., 1994b), and the magnitude for model $\mathrm{A}$ is relatively smaller than that for

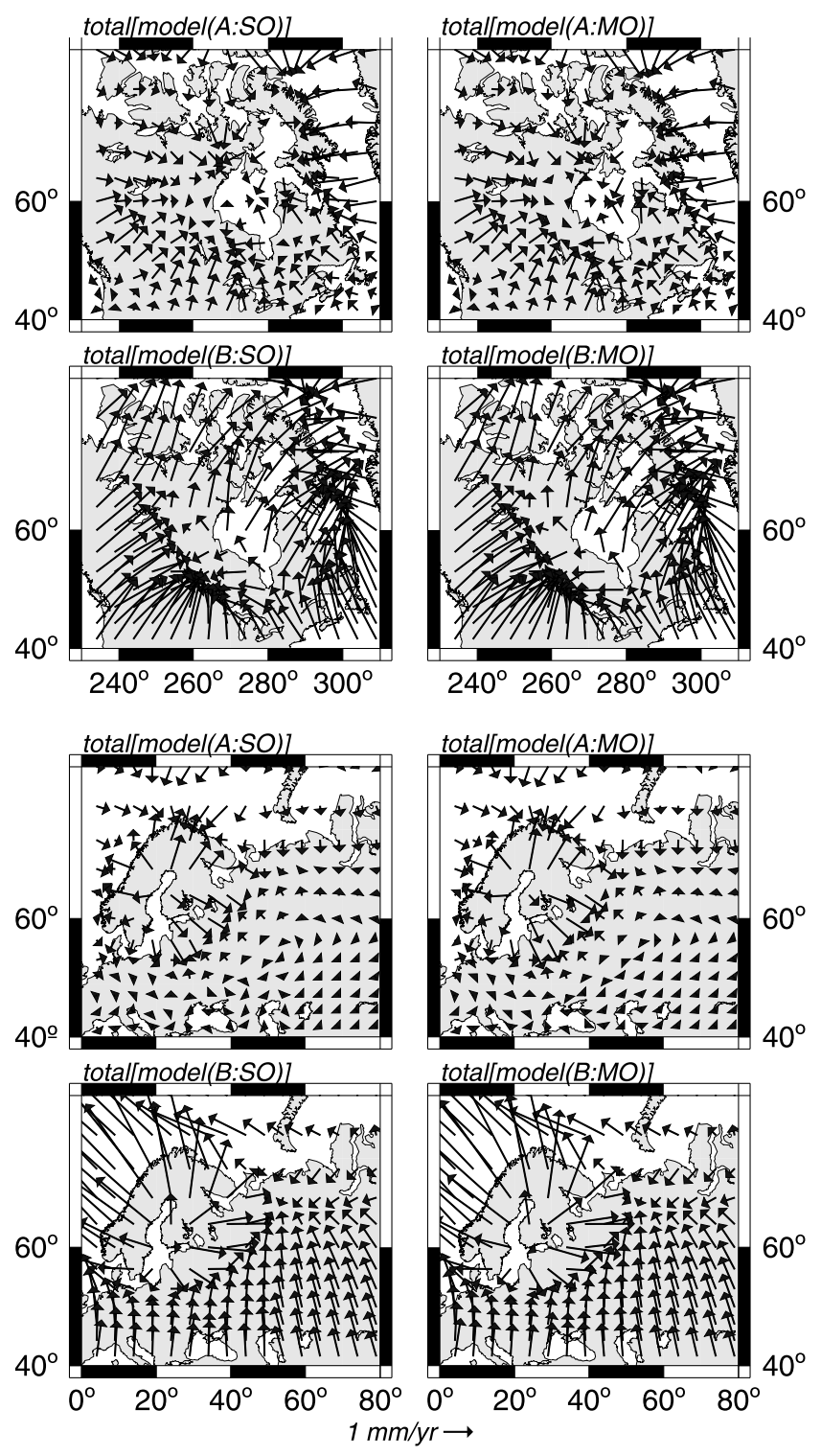

Fig. 10. Predictions of the change in horizontal crustal motions for earth models A and B. Ice model is ARC3+ANT4b. Unit vector is shown in figures. The spatial variations in both regions are not so sensitive to the adoption of ocean function. 


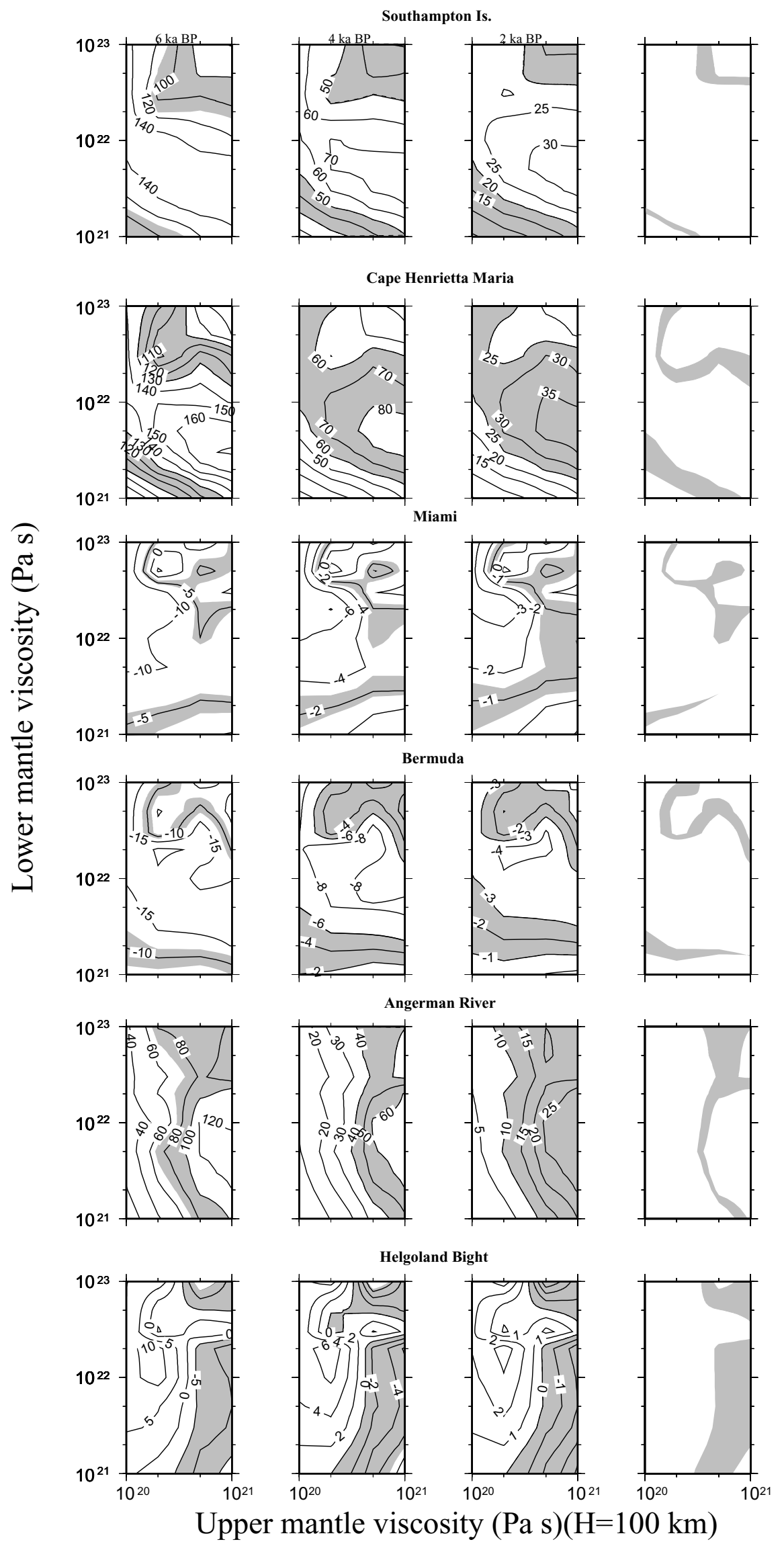

Fig. 11. Predicted relative sea-levels at 6, 4, $2 \mathrm{kyrBP}$ as a function of upper and lower mantle viscosities. The lithospheric thickness (H) is $100 \mathrm{~km}$. Ice model is ARC3+ANT4b and ocean function is model MO. Contour unit is $\mathrm{m}$. The shaded regions indicate the permissible viscosity range solutions for each time. The right-hand figures illustrate the parts of the viscosity range satisfied by the individual solutions from the relative sea-levels at 6,4 , 2 kyrBP. 


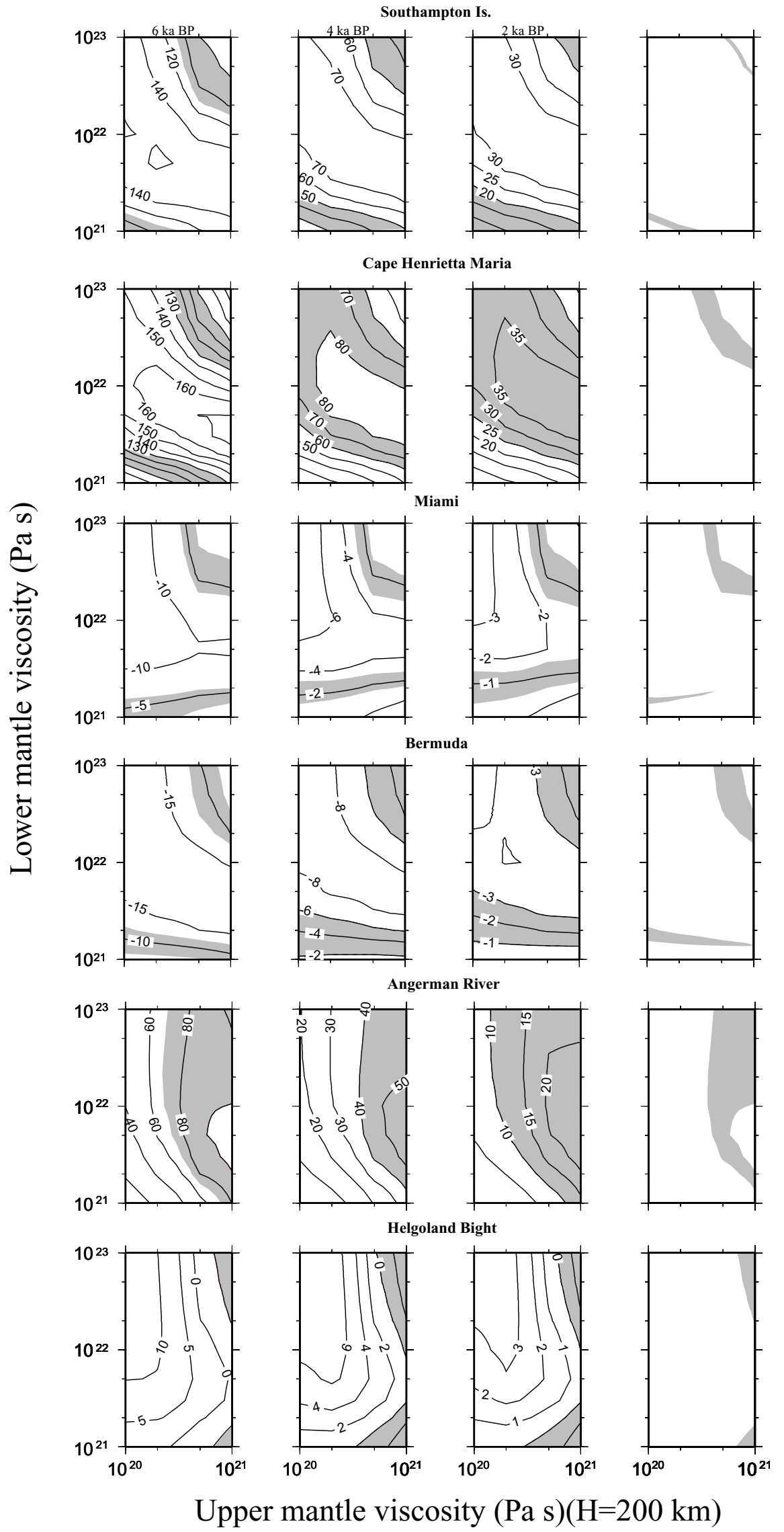

Fig. 12. Predicted relative sea-levels at 6, 4, $2 \mathrm{kyrBP}$ as a function of upper and lower mantle viscosities. The lithospheric thickness $(\mathrm{H})$ is $200 \mathrm{~km}$. Ice model is ARC3+ANT4b and ocean function is model MO. Contour unit is $\mathrm{m}$. The shaded regions indicate the permissible viscosity range solutions for each time. The right-hand figures illustrate the parts of the viscosity range satisfied by the individual solutions from the relative sea-levels at 6 , 4 , 2 kyrBP. 

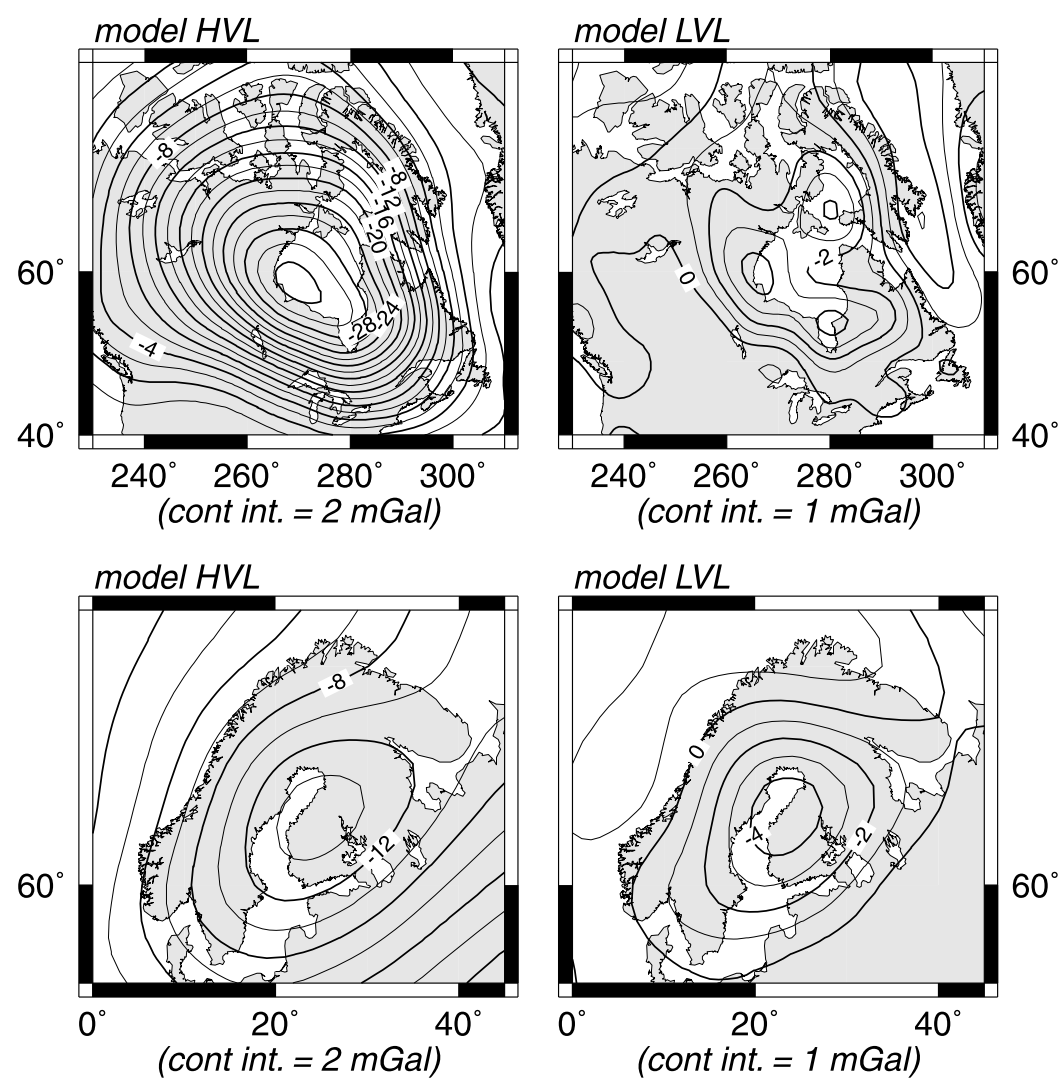

Fig. 13. Free air gravity anomalies for earth models HVL and LVL derived from sea-level observations. The lithospheric thickness is 100 km and the upper mantle viscosity is $5 \times 10^{20} \mathrm{~Pa}$ s for both HVL and LVL models. The lower mantle viscosity for HVL is $3 \times 10^{22} \mathrm{~Pa} \mathrm{~s}$ and that for LVL is $10^{21}$ $\mathrm{Pa}$ s. Ice model is ARC3+ANT4b and ocean function is model MO. Contour unit is $\mathrm{mGal}$.

model B.

\section{Discussion}

Sea-level variations in North America have extensively been examined to estimate the rheological structure of the Earth's mantle (e.g., Cathles, 1975; Wu and Peltier, 1983; Nakada, 1983). But the changes at sites along the east coast of North America such as Boston and New York, close to the margins of Laurentide ice sheets, are equally sensitive to the rheology of the mantle as to the detailed description of the load; generally the latter is inadequately known for the purpose of estimating the Earth's viscosity (Nakada and Lambeck, 1987, 1988b).

Relative sea-level variations at sites far from the edge of the ice sheet limit and at sites in the central part of glaciated region are, however, less sensitive to the details of the ice models than to the mantle structure (Nakada and Lambeck, 1987). In this section, we evaluate the viscosity structure with an assumption that the ice model in the northern hemisphere is represented by the ARC3. The ocean function used here is MO. The assumption for the ice model is, however, not a small assumption. The sea-level changes discussed here are dominantly sensitive to the Arctic ice model. The reason why we adopt the ARC3 (ICE1) for the Arctic ice model is that this model is based on geological and geomorphological observations (Peltier and Andrews, 1976; Nakada and Lambeck, 1988a). The ICE-3G (Tushingham and Peltier, 1991) is, however, constructed by comparing sea-level observations and predictions for a relatively uniform viscosity model. Considering the uncertainty for the ice model, the viscosity model based on this study may require revision. We, however, emphasize that the sea-level changes examined here are mainly sensitive to the gross melting history of the Arctic ice model.

The sea-level observation sites around these regions are shown in Fig. 3. Figures 11 and 12 illustrate the predicted sea-levels at $6,4,2 \mathrm{kyrBP}$ with a function of upper $\left(\eta_{u m}\right)$ and lower mantle viscosities $\left(\eta_{l m}\right)$ and lithospheric thickness $(\mathrm{H})$. The ice model is ARC3+ANT4b. The shaded regions indicate the permissible viscosity space that is consistent with observations for each time. The right-hand figures illustrate the part of the viscosity range satisfied by the individual solutions from the sea-levels at 6, 4, $2 \mathrm{kyrBP}$. The sea-level predictions at sites in the central part of Laurentide ice sheet are sensitive to the lower mantle viscosity, and two permissible viscosity solutions, i.e., higher $\left(10^{22} \sim 10^{23}\right.$ $\mathrm{Pa} \mathrm{s})$ and lower $\left(10^{21} \sim 2 \times 10^{21} \mathrm{~Pa} \mathrm{~s}\right)$ mantle viscosity models, are obtained. These solutions are also supported by the solution for the sea-level variations at Miami and Bermuda away from the edge of the ice sheet limit. These solutions are relatively insensitive to the lithospheric thickness as shown in Figs. 11 and 12.

Figures 11 and 12 also illustrate the predictions at 6, 4, $2 \mathrm{kyrBP}$ and permissible viscosity range satisfied by the individual solutions in northern Europe. The sea-level predictions at these sites are dominantly sensitive to the up- 

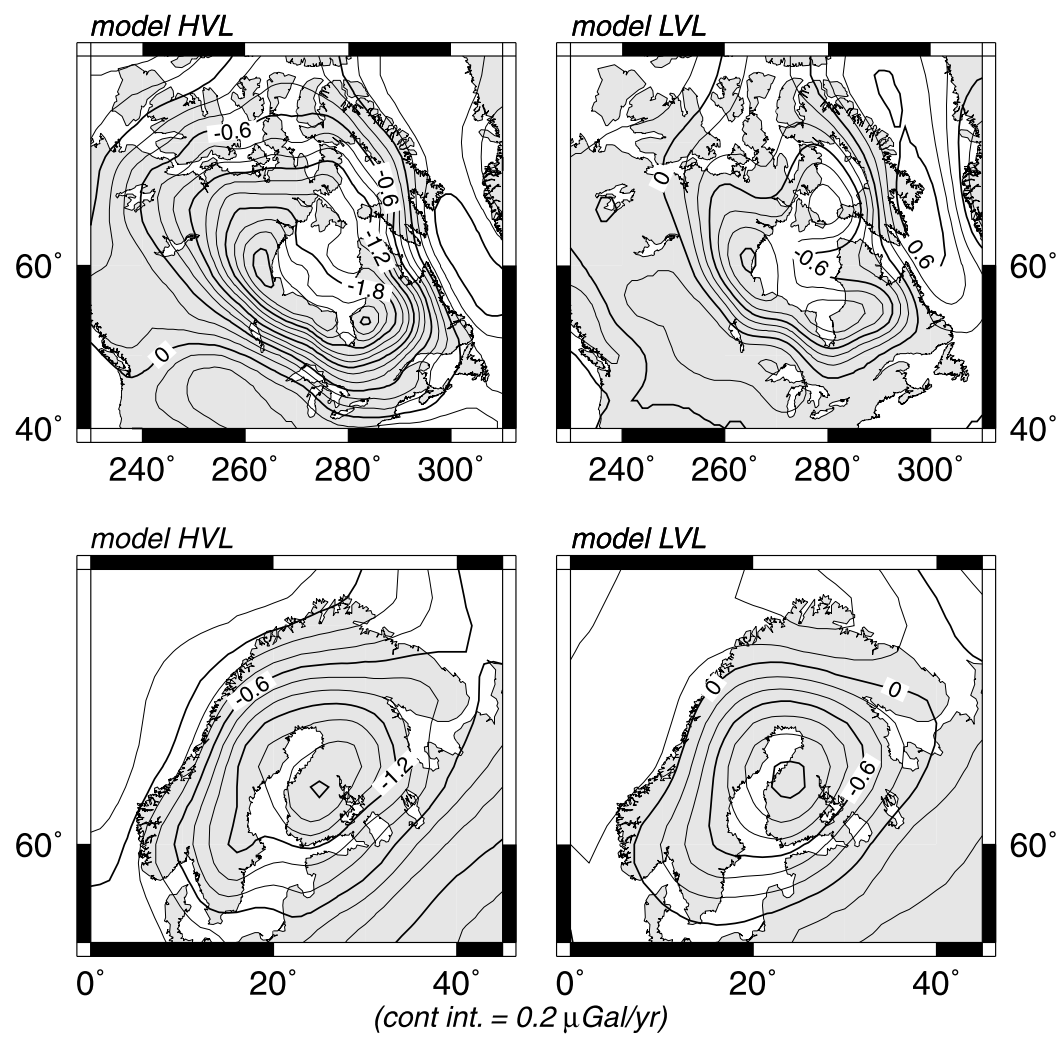

Fig. 14. Solid surface gravity changes for earth models HVL and LVL derived from sea-level observations. Ice model is ARC3+ANT4b and ocean function is model MO. Contour interval is $0.2 \mu \mathrm{Gal} / \mathrm{yr}$.

per mantle viscosity. This is because the wavelength of the Fennoscandian load is relatively small. An acceptable mantle viscosity solution is $3 \sim 10 \times 10^{20} \mathrm{~Pa}$ s for upper mantle viscosity. Lambeck et al. (1998) extensively discussed the sea-level changes in northern Europe, and concluded that the upper mantle viscosity is about $3 \sim 4 \times 10^{20} \mathrm{~Pa} \mathrm{~s}$ and lower mantle is larger by at least an order of magnitude. The inferred upper mantle viscosity for the Fennoscandian region in this study is slightly higher than that by the analyses of Lambeck et al. (1998). A main reason is an overestimation of the Fennoscandian ice load modeled by Denton and Hughes (1981) as indicated by Lambeck et al. (1998).

The free air gravity anomalies for two permissible viscosity models, i.e., model with a lower mantle viscosity of $3 \times 10^{22} \mathrm{~Pa} \mathrm{~s}$ (model HVL) and that with $10^{21} \mathrm{~Pa} \mathrm{~s}$ (model LVL), are illustrated in Fig. 13. The upper mantle viscosity of both models is $5 \times 10^{20} \mathrm{~Pa}$ s and the lithospheric thickness is $100 \mathrm{~km}$. The minimum value of the observed free air gravity anomaly at the Hudson Bay region is about $-50 \mathrm{mGal}$ (see Fig. 5), and the prediction based on the model HVL is about $-30 \mathrm{mGal}$. Two different explanations for the cause of observed negative anomaly have been proposed. One is due to incomplete postglacial rebound, which is supported by the fact that there is remarkable correlation between spatial variations of gravity anomaly and the geometry of the Laurentide ice sheet during the LGM (Walcott, 1973). The other is due to dynamic topography associated with convective downwelling inferred from the higher mantle seismic velocities in this region (Hager and Clayton, 1989; Pari and Peltier, 1996). Simons and Hager (1997) analyzed the lo- cal correlation between observed gravity field and seismic velocity anomalies, and suggested that half of the gravity anomaly in Hudson Bay is attributed to the incomplete postglacial rebound. Therefore, study by Simons and Hager (1997) seems to support the prediction based on a high viscosity model HVL.

Figure 14 illustrates the solid surface gravity changes for models HVL and LVL. Solid surface gravity change due to glacial rebound is different from that due to the convection. Thus, the gravity change due to the convection model, which is considered to be steady state flow (Pari and Peltier, 1996), is nearly equal to zero. That due to postglacial rebound is, however, negative because of incomplete postglacial rebound. Lambert et al. (1996) observed the absolute gravity from 1988 to 1995 years at Churchill, and obtained the gravity change to be $-1.3 \pm 0.6 \mu \mathrm{Gal} / \mathrm{yr}$. The gravity change based on the observations from 1988 to 2000 is $-2.13 \pm 0.23$ $\mu \mathrm{Gal} / \mathrm{yr}$ (Lambert et al., 2001). We adopt this value as the observational constraint. In order to constrain the viscosity model, we evaluated the minimum values for free-air gravity anomaly and solid surface gravity change as the function of the upper and lower mantle viscosities (Fig. 15). The lithospheric thickness, which is less sensitive to the predictions of these observables, is assumed to be $100 \mathrm{~km}$. In Hudson Bay region, permissible ranges inferred from these observations (Lemoine et al., 1998; Lambert et al., 1996, 2001) and study by Simons and Hager (1997) are indicative of the upper mantle viscosity of $4 \sim 10 \times 10^{20} \mathrm{~Pa} \mathrm{~s}$ and the lower mantle viscosity of greater than $10^{22} \mathrm{~Pa} \mathrm{~s}$.

Figure 16 illustrates the surface deformation rates. 


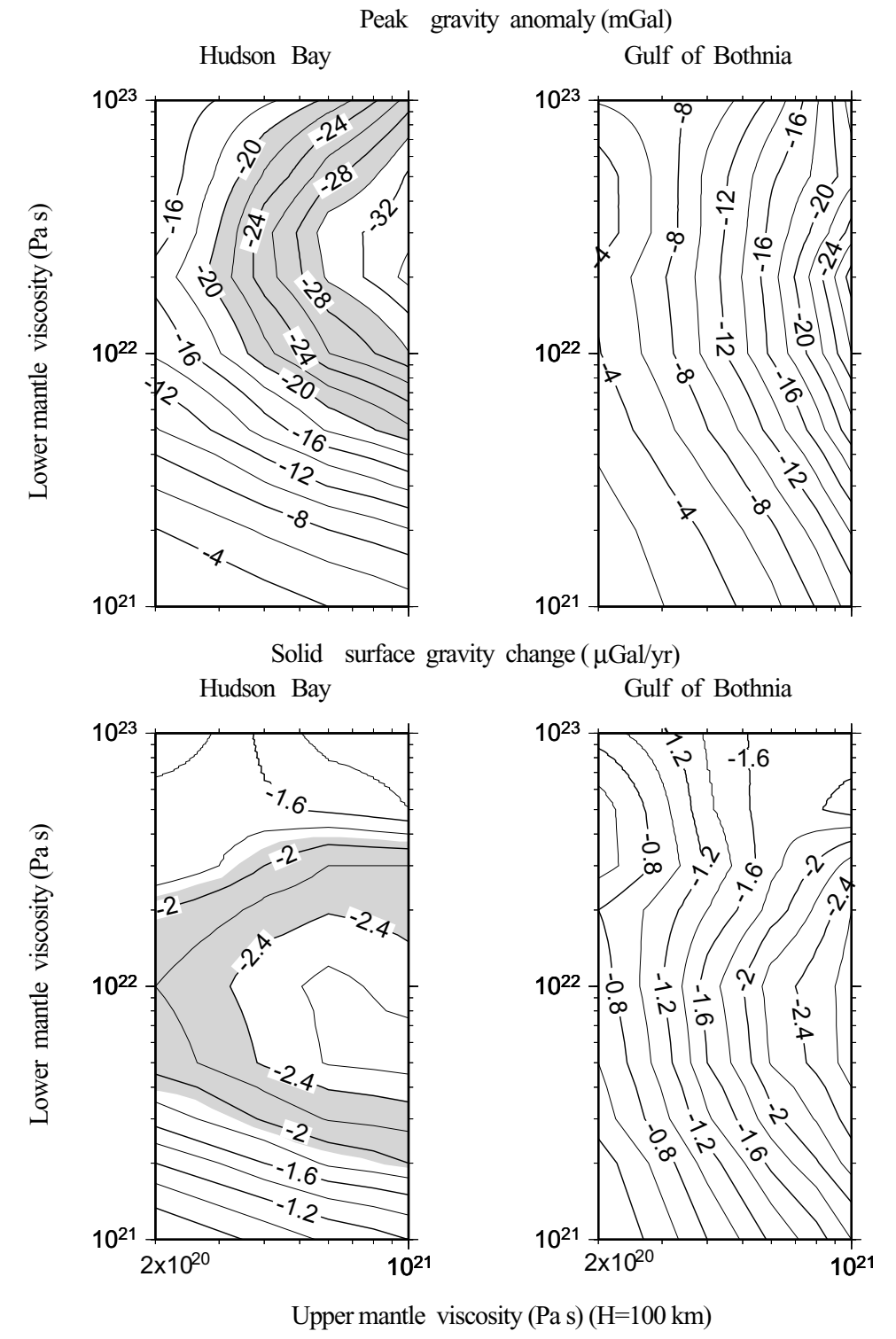

Fig. 15. Predicted peak free air gravity anomaly and solid surface gravity change in Hudson Bay and Gulf of Bothnia regions as a function of the upper and lower mantle viscosities. The lithospheric thickness is $100 \mathrm{~km}$. Ice model is ARC3+ANT4b and ocean function is model MO. The shaded regions indicate the permissible viscosity solutions.

Mitrovica et al. (1994b) showed predictions based on ICE3G (Tushingham and Peltier, 1991), ICE1 (Peltier and Andrews, 1976) and disk ice load model adopted by James and Morgan (1990). Then, they suggested that calculated deformation fields strongly depend on the spatial geometry of the ice load. Our results based on ARC $3+$ ANT4b indicate that the predicted deformation fields are very sensitive to the lower mantle viscosity (see also Mitrovica et al., 1994b). James and Lambert (1993) have predicted the crustal motions due to postglacial rebound, and suggested that horizontal motions are much sensitive to the mantle viscosity than radial motions. Our conclusion, however, indicates that spatial variations and amplitudes of both horizontal and vertical crustal motions are equally sensitive to the viscosity structure of the mantle.

\section{Conclusion}

In this study, we confirmed that a realistic ocean func- tion including the effects of palaeotopography, distribution of ice sheet and also water influx in previously ice-covered and subgeoidal geographic regions proposed by Milne et al. (1999) is required to precisely evaluate sea-level variations and other geophysical signals associated with glacio-hydro isostatic adjustment. We then examined the viscosity structure of the mantle based on geophysical signals at sites in and around the glaciated regions.

Comparison between the predictions with a ocean function defined by present topography (SO) and those based on the ocean function constructed by both palaeotopography, ice sheet geometry and water influx (MO) indicates that the water loads significantly affect the predictions of relative sea-level changes and other geophysical observations for the Hudson Bay region. In particular, the predictions of these signals for an earth model with a low lower mantle viscosity $\left(\eta_{l m} \sim 10^{21} \mathrm{~Pa} s\right)$ are sensitive to the accuracy of the ocean function because of the significant contribution of wa- 

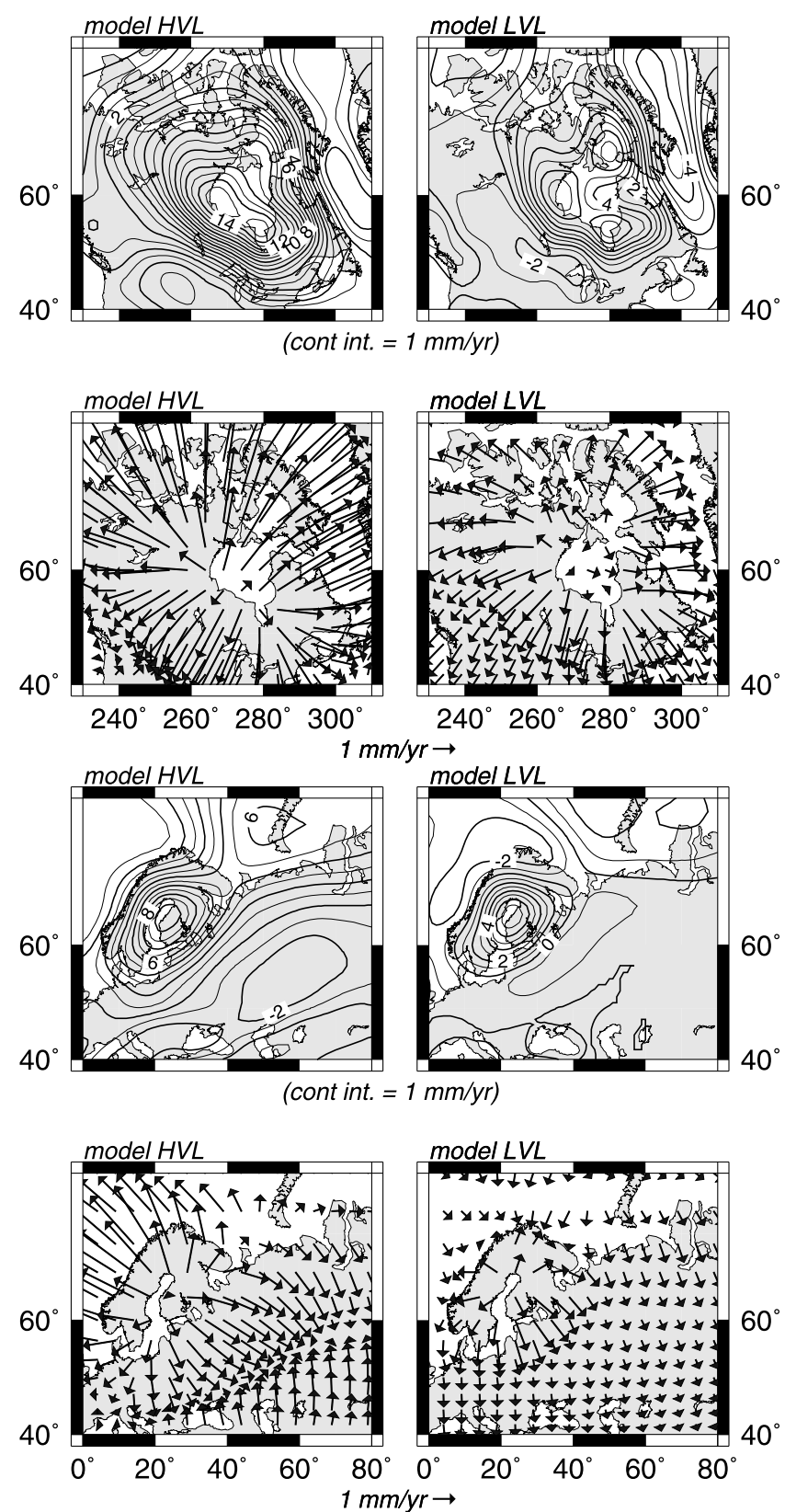

Fig. 16. Present-day surface vertical and horizontal rates for earth models HVL and LVL. Ice model is ARC3+ANT4b and ocean function is model MO.

ter loads. In the Fennoscandian region, however, the predictions for model MO are nearly equal to those by SO model. This is because the width of the Gulf of Bothnia is relatively smaller than that of the Hudson Bay. Thus, accurate evaluation of water loads is very important for the construction of ice models and also to estimate the viscosity structure based on the geophysical observables due to glacial rebound as indicated by Milne et al. (1999).

We have also inferred the viscosity structure from sealevel variations and gravity anomalies for North America and northern Europe, in which the ice model of ARC3+ ANT4b is assumed and MO model is adopted as ocean function. Relative sea-levels in the Fennoscandian region, which are mainly sensitive to the upper mantle viscosity, suggest the upper mantle viscosity of $3 \sim 10 \times 10^{20} \mathrm{~Pa} \mathrm{~s}$, consistent with the results by Lambeck et al. $(1990,1998)$ and Mitrovica (1996). Gravity anomalies and recent crustal movements are, however, sensitive to lower mantle viscosity, and more observational data are required to constrain the lower mantle viscosity. On the other hand, sea-level observations, free-air gravity anomalies and solid surface gravity change in North America indicate the lower mantle viscosity of greater than $10^{22} \mathrm{~Pa} \mathrm{~s}$ and the upper mantle viscosity of about $4 \sim 10 \times 10^{20} \mathrm{~Pa} \mathrm{~s}$.

Acknowledgments. We are very grateful for the constructive reviews by Drs. J. X. Mitrovica and S. Yoshida. The constructive reviews by them significantly improved the manuscript.

\section{References}

Cathles, L. M., The Viscosity of the Earth's Mantle, Princeton University Press, Princeton, 1975.

Denton, G. H. and T. J. Hughes, The Last Great Ice Sheets, Wiley, New York, 1981.

Dziewonski, A. M. and D. L. Anderson, Preliminary reference Earth model, Phys. Earth Planet. Int., 25, 297-356, 1981.

Farrell, W. E., Deformation of the Earth by surface loads, Rev. Geophys. Space Phys., 10, 761-797, 1972.

Farrell, W. E. and J. A. Clark, On postglacial sealevel, Geophys. J. R. astr. Soc., 46, 637-667, 1976.

Fjeldskaar, W. and L. M. Cathles, Rheology of mantle and lithosphere inferred from post-glacial uplift in Fennoscandia, in Glacial Isostasy, Sea-level and Mantle Rheology, Kluwer, The Netherlands, 1991.

Forte, A. M. and J. X. Mitrovica, New inferences of mantle viscosity from joint inversion of long-wavelength mantle convection and post-glacial rebound data, Geophys. Res. Lett., 23, 1147-1150, 1996.

Hager, B. H., Subducted slabs and the geoid: constraints on mantle rheology and flow, J. Geophys. Res., 89, 6003-6015, 1984.

Hager, B. H. and R. W. Clayton, Constraints on the structure of mantle convection using seismic observations, flow models, and the geoid, in Mantle Convection: Plate Tectonics and Global Dynamics, Gordon and Breach, Newark, N. J., 1989.

Haskell, N. A., The motion of a viscous fluid under a surface load, Part II, Physics, 7, 56-61, 1936.

James, T. S. and E. R. Ivins, Predictions of Antarctic crustal motions driven by present-day ice sheet evolution and by isostatic memory of the last glacial maximum, J. Geophys. Res., 103, 4993-5017, 1998.

James, T. S. and A. Lambert, A comparison of VLBI data with the ICE-3G glacial rebound model, Geophys. Res. Lett., 20, 871-874, 1993.

James, T. S. and W. J. Morgan, Horizontal motions due to postglacial rebound, Geophys. Res. Lett., 17, 957-960, 1990

Johnston, P., The effect of spatially non-uniform water loads on the prediction of sea-level change, Geophys. J. Int., 114, 615-634, 1993.

Kaufmann, G., The onset of Pleistocene glaciation in the Barents Sea: implications for glacial isostatic adjustment, Geophys. J. Int., 131, 281292, 1997.

Lambeck, K. and M. Nakada, Late Pleistocene and Holocene sea-level change along the Australian coast, Palaeogeogr. Palaeoclimatol. Palaeoecol., 89, 143-176, 1990.

Lambeck, K., P. Johnston, and M. Nakada, Holocene glacial rebound and sea-level change in NW Europe, Geophys. J. Int., 103, 451-468, 1990.

Lambeck, K., P. Johnston, C. Smither, and M. Nakada, Glacial rebound of the British Isles-III. Constraints on mantle viscosity, Geophys. J. Int., 125, 340-354, 1996

Lambeck, K., C. Smither, and P. Johnston, Sea-level change, glacial rebound and mantle viscosity for northern Europe, Geophys. J. Int., 134 102-144, 1998.

Lambert, A., T. S. James, J. O. Liard, and N. Courtier, The role and capability of absolute gravity measurements in determining the temporal variations in the Earth's gravity field, in Global Gravity Field and its Temporal Variations, Int. Assoc. Geod. Symp., 116, 20-29, 1996.

Lambert, A., N. Courtier, G. S. Sasagawa, F. Klopping, D. Winester, T. S. James, and J. O. Liard, New Constraints on Laurentide postglacial rebound from absolute gravity measurements, Geophys. Res. Lett., 2010, 2109-2112, 2001.

Lemoine, F. G., N. K. Pavlis, S. C. Kenyon, R. H. Rapp, E. C. Pavlis, and B F. Chao, New high-resolution model developed for Earth's gravitational 
field, EOS Trans. Am. Geophys. Un., 79, 113-118, 1998.

McConnell, R. K., Isostatic adjustment in layered Earth, J. Geophys. Res., 70, 5171-5188, 1965.

Milne, G. A., Refining models of the glacial isostatic adjustment process, $\mathrm{PhD}$ Thesis, University of Toronto, Toronto, 1998.

Milne, G. A. and J. X. Mitrovica, The influence of time-dependent oceancontinent geometry on predictions of post-glacial sea level change in Australia and New Zealand, Geophys. Res. Lett., 25-6, 793-796, 1998.

Milne, G. A., J. X. Mitrovica, and J. L. Davis, Near-field hydro-isostasy: the implementation of a revised sea-level equation, Geophys. J. Int., 139, 464-482, 1999.

Milne, G. A., J. L. Davis, J. X. Mitrovica, H.-G. Scherneck, J. M. Johansson, M. Vermeer, and H. Koivula, Space-geodetic constraints on glacial isostatic adjustment in Fennoscandia, Science, 291, 2381-2385, 2001.

Mitrovica, J. X., Haskell[1935] revisited, J. Geophys. Res., 101, 555-569, 1996.

Mitrovica, J. X. and W. R. Peltier, Pleistocene deglaciation and the global gravity field, J. Geophys. Res., 94, 13651-13671, 1989.

Mitrovica, J. X. and W. R. Peltier, On post-glacial geoid subsidence over the equatorial oceans, J. Geophys. Res., 96, 20053-20071, 1991.

Mitrovica, J. X. and W. R. Peltier, Constraints on mantle viscosity based upon the inversion of post-glacial uplift data from the Hudson Bay region, Geophys. J. Int., 122, 353-377, 1995.

Mitrovica, J. X., J. L. Davis, and I. I. Shapiro, A spectral formalism for computing three-dimensional deformations due to surface loads. 1 . Theory, J. Geophys. Res., 99, 7057-7073, 1994a.

Mitrovica, J. X., J. L. Davis, and I. I. Shapiro, A spectral formalism for computing three-dimensional deformations due to surface loads. 2 . Present-day glacial isostatic adjustment, J. Geophys. Res., 99, 70757101, 1994b.

Munk, W. H. and G. J. F. MacDonald, The Rotation of the Earth, Cambridge University Press, New York, 1960.

Nakada, M., Rheological structure of the Earth's mantle derived from the glacial rebound in Laurentide, J. Phys. Earth, 31, 349-386, 1983.

Nakada, M., Holocene sea levels in oceanic island: implications for the rheological structure of the Earth's mantle, Tectonophys., 121, 263-276, 1986.

Nakada, M. and K. Lambeck, Glacial rebound and relative sea-level variations: a new appraisal, Geophys. J. R. astr. Soc., 90, 171-224, 1987.

Nakada, M. and K. Lambeck, The melting history of the late Pleistocene Antarctic ice sheet, Nature, 333, 36-40, 1988a.

Nakada, M. and K. Lambeck, Non-uniqueness of lithospheric thickness estimates based on glacial rebound data along the east coast of North America, in Mathematical Geophysics, pp. 347-361, Reidel, Dordecht, $1988 b$.
Nakada, M. and K. Lambeck, Late Pleistocene and Holocene sea-level changes in Australian region and mantle rheology, Geophys. J., 96, 497$517,1989$.

Nakada, M. and K. Lambeck, Late Pleistocene and Holocene sea-level change: evidence for lateral mantle viscosity structure?, in Glacial Isostasy, Sea-level and Mantle Rheology, Kluwer, The Netherlands, 1991.

Nakada, M., R. Kimura, J. Okuno, K. Miriwaki, H. Miura, and H. Maemoku, Late Pleistocene and Holocene melting history of the Antarctic ice sheet derivced from sea-level variations, Mar. Geo., 167, 85-103, 2000.

Okuno, J. and M. Nakada, Rheological structure of the upper mantle inferred from the Holocene sea-level change along the west coast of Kyushu, Japan, in Dynamics of the Ice Age Earth: A Modern Perspective, pp. 443-458, Trans Tech Publications Ltd, Brandrain, Switzerland, 1998.

Pari, G. and W. R. Peltier, The free-air gravity constraint on subcontinental mantle dynamics, J. Geophys. Res., 101, 28105-28132, 1996.

Peltier, W. R., The impulse response of a Maxwell Earth, Rev. Geophys., 12, 649-669, 1974.

Peltier, W. R., 'Implicit ice' in the global theory of glacial isostatic adjustment, Geophys. Res. Lett., 25, 3955-3958, 1998.

Peltier, W. R. and J. T. Andrews, Glacial isostatic adjustment-I. The forward problem, Geophys. J. R. astr. Soc., 46, 605-646, 1976.

Simons, M. and B. H. Hager, Localization of the gravity field and the signature of glacial rebound, Nature, 390, 500-504, 1997.

Tushingham, A. M. and W. R. Peltier, ICE-3G: a new global model of late Pleistocene deglaciation based upon geophysical predictions of postglacial relative sea level change, J. Geophys. Res., 96, 4497-4523, 1991.

Tushingham, A. M. and W. R. Peltier, Validation of ICE-3G model of Würm-Wisconsin deglaciation using a global data base of relative sea level histories, J. Geophys. Res., 97, 3285-3304, 1992.

Walcott, R. I., Late Quaternary vertical movements in eastern North America: Quantitative evidence of glacial-isostatic rebound, Rev. Geophys., 10, 849-884, 1972.

Walcott, R. I., Structure of the earth from glacio-isostatic rebound, Annu. Rev. Earth Planet. Sci., 1, 15-37, 1973.

Walcott, R. I., Rheological models and observational data of glacio-isostatic rebound, in Earth Rheology, Isostasy and Eustasy, Wiley, New York, 1980.

Wu, P. and W. R. Peltier, Glacial isostatic adjustment and the free-air gravity anomaly as a constraint on deep mantle viscosity, Geophys. J. R. astr. Soc., 74, 377-450, 1983.

J. Okuno (e-mail: okuno@eri.u-tokyo.ac.jp) and M. Nakada 